\title{
Development and application of a spectrophotometric method in quality evaluation of benzimidazole anthelminthics in Nairobi city county
}

\author{
Johnson K. Murage ${ }^{1 *}$ (D), Beatrice K. Amugune ${ }^{2}$, Peter Njogu ${ }^{2}$ and Stanley Ndwigah ${ }^{2}$
}

\begin{abstract}
Background: Neglected tropical diseases (NTDs) are a group of communicable diseases which are prevalent in the tropics affecting more than one billion people. Treatment and prevention of these infections is very costly to developing economies. Helminthiases are classified among NTDs. The communities afflicted are poor and have limited access to essential resources for their livelihood. Poor-quality drugs for NTDs may lead to death or prolonged treatment without achieving the desired results. The limited resources used in purchasing poor-quality drugs will therefore be wasted instead of being put to good use.

Most of the methods available for the analysis of benzimidazole anthelminthics utilize high-performance liquid chromatography. They are therefore time consuming, require sophisticated and expensive equipment, utilize rare and expensive reagents and solvents, and call for skilled personnel. A simple, rapid, and inexpensive ultraviolet spectrophotometric method of analysis would therefore come in handy especially in the analysis of many samples as occurs during post-authorization market surveillance for quality.

Results: The suitable solvent for the spectroscopic analysis was established as $0.1 \mathrm{M}$ methanolic $\mathrm{HCl}$. The wavelength of analysis was set at $294 \mathrm{~nm}$. Upon validation, the method was found to have good linearity. The range over which linearity was established was way beyond the 80 to $120 \%$ of the working concentration specified by the ICH. The method exhibited good precision.

Out of 32 commercial samples analyzed, five (15.6\%) did not comply with compendial specifications. Intra-brand batch variation was also observed. Out of three batches of product A002T analyzed, one did not comply with compendial specifications.

Conclusion: A major limitation in the analysis of benzimidazole anthelminthics is the lack of reliable, simple, rapid, and low-cost methods of analysis with high throughput. The developed method serves to fill this gap. It can be used in the analysis of raw materials and finished products. It can also be used in the establishment of the quality of products prior to registration. The method will prove very useful in post-market surveillance of quality of benzimidazole anthelminthics.
\end{abstract}

Keywords: Benzimidazole anthelminthics, Albendazole, Mebendazole, UV spectroscopy

\footnotetext{
*Correspondence: muragejohnson@gmail.com

${ }^{1}$ Mount Kenya University, P O Box 342 - 01000, Thika, Kenya

Full list of author information is available at the end of the article
}

\section{Springer Open}

(0) The Author(s). 2020 Open Access This article is licensed under a Creative Commons Attribution 4.0 International License, which permits use, sharing, adaptation, distribution and reproduction in any medium or format, as long as you give appropriate credit to the original author(s) and the source, provide a link to the Creative Commons licence, and indicate if changes were made. The images or other third party material in this article are included in the article's Creative Commons licence, unless indicated otherwise in a credit line to the material. If material is not included in the article's Creative Commons licence and your intended use is not permitted by statutory regulation or exceeds the permitted use, you will need to obtain permission directly from the copyright holder. To view a copy of this licence, visit http://creativecommons.org/licenses/by/4.0/. 


\section{Background}

Benzimidazole anthelminthics are broad-spectrum anthelminthics widely used both in human and veterinary medicine. Helminth infections are classified as neglected tropical diseases (NTDs) by the World Health Organization (WHO) [1]. Most of the drugs that are available for the treatment of helminthic infections in humans were first developed as veterinary medicines [2]. Benzimidazole anthelminthics, mainly albendazole and mebendazole (Fig. 1), play a key role in the treatment of soil-transmitted helminthiases (including ascariasis, trichuriasis, hookworms, threadworm, and pinworm infections) [3]. Further, albendazole is the first-line treatment for hydatid disease [4]. Albendazole is particularly preferred because of its convenience of administration as a single dose in most infections. Affordable generic formulations are also available for both albendazole and mebendazole.

Due to a dearth of effective anthelminthics for human use, the quality of the few available anthelminthics should be guarded for therapeutic success. Various analytical methods have been reported for the analysis of albendazole and mebendazole in bulk and dosage forms. Highperformance liquid chromatographic (HPLC) methods, including those in the United States pharmacopeia (USP) and British Pharmacopoeia (BP), have been widely developed for these drugs $[5,6]$. Very little effort has been directed towards the development of an ultraviolet (UV) spectroscopic method of analysis despite its many advantages. Compared to HPLC, UV spectroscopy is faster and requires less analyst skill and the equipment is less expensive and easier to operate and maintain. Additionally, with portable UV spectrophotometers, analysis can be performed in areas remote from the major laboratory when necessary. To date, only one UV spectroscopic method developed by Agrawal et al. has been reported [7] .

The biochemical target for benzimidazole anthelminthics is the $\beta$-tubulin, a cytoskeletal protein which is a building block of microtubules present in all eukaryotic cells. Microtubules are critical cytoskeletal polymers which are made of repeating $\alpha$ - and $\beta$ tubulin dimers. Microtubules are involved in cellular morphology, cell transport, cell motility, and cell division [8]

\section{Methods}

\section{Materials}

Methanol of HPLC grade (Finar Ltd, India) was obtained from Chemoquip Ltd, Nairobi. Analytical grade concentrated hydrochloric acid $(\mathrm{HCl})$, sodium lauryl sulfate (SLS), and albendazole and mebendazole working standards were provided by the Drug Analysis and Research Unit (DARU) of the Department of Pharmaceutical Chemistry, University of Nairobi. Commercial pharmaceutical products containing albendazole or mebendazole active pharmaceutical ingredient (API) were acquired from wholesalers in the Central Business District $(\mathrm{CBD})$ and the outskirts of the city of Nairobi, Kenya. Throughout the period of the study, nine albendazole and two mebendazole brands were analyzed.

\section{Instrumentation}

All weights were taken using a Sartorius top-loading electronic weighing balance (Sartorius GMBH, Germany). Absorbance readings were read on a Genesys $10 \mathrm{~S}$ UV-Vis Spectrophotometer (ThermoFisher Scientific, China).

A Merck Hitachi HPLC machine (Hitachi Ltd, Tokyo, Japan), with a Varian HPLC column, $250 \times 4.0 \mathrm{~mm}$, $5 \mu \mathrm{m}$ LiChristopher 100-5 RP 18 end capped, kindly availed by the National Quality Control Laboratory (NQCL), Nairobi, Kenya, was used for the orthogonal analysis of commercial samples. It was equipped with an L-7100 low pressure quaternary pump, an L-m7200 autosampler, an L-7400 variable UV detector set at 308 $\mathrm{nm}$, an L-7350 thermostatic column oven maintained at $40{ }^{\circ} \mathrm{C}$, and an L-7000 computer interphase.

\section{Method development Key considerations}

A method from literature developed by Agrawal et al. [7] was adapted for the analysis of both albendazole and mebendazole at a single wavelength using a common solvent. The key considerations in development of the method included choice of solvent in which both albendazole and mebendazole exhibited adequate solubility, determination of optimal wavelength of analysis, and determination of suitable working concentration. To make the analytical process simple, analysis needed to be performed at a common wavelength at which both APIs<smiles>CCCCCCCCSc1ccc2[nH]c(NC(=O)OC)nc2c1</smiles>

Albendazole<smiles>COC(=O)Nc1nc2cc(C(=O)c3ccccc3)ccc2[nH]1</smiles>

Mebendazole

Fig. 1 Chemical structures of albendazole and mebendazole 
showed adequate absorbance with minimal interference from excipients, related substances, and degradation products possibly present in analytical samples. A working concentration within the linear range of absorption signal of both APIs also had to be determined.

\section{Determination of a suitable solvent}

Two solvents were investigated for the dissolution of both the bulk APIs and the commercial samples. These were $0.1 \mathrm{M} \mathrm{HCl}$ containing $0.05 \%$ SLS and $0.1 \mathrm{M}$ methanolic $\mathrm{HCl}$. The former had been used in the Agrawal et al. method [7] while the latter was used by Al-Kurdi et al. [5].

\section{Choice of wavelength of analysis}

To decide on a single wavelength for both analytes, the UV spectra of each API at a nominal concentration of $12 \mu \mathrm{g} / \mathrm{mL}$ in $0.1 \mathrm{M}$ methanolic $\mathrm{HCl}$ were run independently between 200 and $400 \mathrm{~nm}$. The two spectra were then overlaid. Two wavelengths (233 and $294 \mathrm{~nm}$ ) were initially chosen for further investigation.

\section{Choice of working concentration}

The appropriateness of a concentration of $12 \mu \mathrm{g} / \mathrm{mL}$ as used by Agrawal et al. [7] was investigated and was found to fall within the linear range for both APIs.

\section{Adapted method}

After the preliminary investigations ("Determination of a suitable solvent," "Choice of wavelength of analysis," and "Choice of working concentration" sections), optimal conditions for the method were suggested as UV absorbance of a $12-\mu \mathrm{g} / \mathrm{mL}$ solution of each API in $0.1 \mathrm{M}$ methanolic $\mathrm{HCl}$ and measured at 294-nm wavelength. This method was taken through a validation process to assess its suitability.

\section{Method validation Linearity and range}

A $1.0-\mathrm{mg} / \mathrm{mL}$ stock solution of each of the two APIs was prepared by weighing $50 \mathrm{mg}$ of the respective API into a $50-\mathrm{mL}$ volumetric flask, dissolving in minimum $0.1 \mathrm{M}$ methanolic $\mathrm{HCl}$, and the solution made to volume with the same solvent. Working solutions were prepared by transferring aliquots of the stock solution into $25-\mathrm{mL}$ volumetric flasks and making to volume using $0.1 \mathrm{M}$ methanolic $\mathrm{HCl}$ producing ten solutions of $4,8,12,16$, $20,24,28,32,36$, and $40 \mu \mathrm{g} / \mathrm{mL}$ nominal concentrations. This represented a range of 33.3 to $333.3 \%$ of the working concentration. The absorbances of these solutions were read at $294 \mathrm{~nm}$, and the data obtained plotted using a Microsoft Excel spreadsheet and subjected to linear regression analysis.

\section{Precision}

Repeatability and intermediate precision were determined in this study as outlined in the sections "Repeatability" and "Intermediate precision." Reproducibility was not determined as the study did not involve a collaborating laboratory.

Repeatability About $50 \mathrm{mg}$ of each API was weighed into a $50-\mathrm{mL}$ volumetric flask, dissolved in minimum $0.1 \mathrm{M}$ methanolic $\mathrm{HCl}$, and made to volume with the same solvent. A $0.3-\mathrm{mL}$ aliquot of this solution was transferred to a $25-\mathrm{mL}$ volumetric flask and made to volume with the same solvent to give a final solution. Absorbance of the test solution was determined on the same day six times at $294 \mathrm{~nm}$. The standard deviation, relative standard deviation, and coefficient of variation $(\mathrm{COV})$ of these data were then calculated.

Intermediate precision The procedure for the determination of repeatability ("Repeatability" section) was followed after several days.

\section{Accuracy}

The accuracy of the method was established by adding a known amount of the analyte (API) to a solution of a commercial product whose API concentration was 80,100 , and $120 \%$ of the working concentration $(12 \mu \mathrm{g} / \mathrm{mL})$ [9]. The percentage recovery of the analyte in each solution was then determined. The determinations were done in triplicate.

\section{Orthogonal HPLC analysis}

To compare the reliability and accuracy of the developed method with that of a validated method in routine use, the HPLC procedure for the analysis of albendazole as described in the USP 2018 was used. The suspension dosage form of one of the commercial products was analyzed. The results obtained from both methods were then compared.

\section{Specificity}

The process of testing for accuracy ("Accuracy" section) involving the analysis of the API in the presence of excipients, possible related compounds, and degradation products was additionally used to assess the specificity of the developed method.

\section{Sensitivity}

As a measure of sensitivity, the limits of detection and quantitation (LOD and LOQ) were determined by computing the standard deviation $(\sigma)$ of the response and the slope $(S)$ of the linearity plot [9]. The standard deviation was determined by measuring the absorbance of the blank $(0.1 \mathrm{M}$ methanolic $\mathrm{HCl})$ six times and calculating the standard deviation of the responses.

The LOD and LOQ were calculated using Eqs. 1 and 2: 


$$
\mathrm{LOD}=3.3 \sigma / \mathrm{S}
$$

$$
\mathrm{LOD}=10 \sigma / \mathrm{S}
$$

\section{Analysis of commercial samples}

The linear plots used in the determination of linearity and range ("Linearity and range" section) were also used as the calibration curves for content determination of both APIs.

\section{Sample preparation}

Tablet dosage forms Twenty tablets were accurately weighed and pulverized to a fine powder. An amount of the powder equivalent to $50 \mathrm{mg}$ of the respective API was accurately weighed into a $50-\mathrm{mL}$ volumetric flask. About $25 \mathrm{~mL}$ of $0.1 \mathrm{M}$ methanolic $\mathrm{HCl}$ was added and the mixture shaken to dissolve. The solution was ultrasonicated for $5 \mathrm{~min}$ and made to volume with the same solvent and the solution filtered. A $0.3-\mathrm{mL}$ aliquot of the filtrate was pipetted into a $25-\mathrm{mL}$ volumetric flask and made to volume with the same solvent. The absorbance of this solution was read at $294 \mathrm{~nm}$. The samples were prepared in triplicate.

Suspension dosage forms An amount of the suspension equivalent to $50 \mathrm{mg}$ of the respective API (as determined by the use of a density bottle) was accurately weighed into a $50-\mathrm{mL}$ volumetric flask. A minimum amount of $0.1 \mathrm{M}$ methanolic $\mathrm{HCl}$ was added and the flask shaken to dissolve. The solution was ultrasonicated for $5 \mathrm{~min}$ and made to volume with $0.1 \mathrm{M}$ methanolic $\mathrm{HCl}$ and the solution filtered. A $0.3-\mathrm{mL}$ aliquot of the filtrate was pipetted into a $25-\mathrm{mL}$ volumetric flask and made to volume with the same solvent. The absorbance of this solution was read at $294 \mathrm{~nm}$. The samples were prepared in triplicate.

\section{Results}

Method development

Choice of solvent

Both APIs were found to have better solubility in $0.1 \mathrm{M}$ methanolic $\mathrm{HCl}$ than in $0.1 \mathrm{M} \mathrm{HCl}$ containing $0.05 \%$ SLS. Therefore, $0.1 \mathrm{M}$ methanolic $\mathrm{HCl}$ was used for further development of the analytical method.

\section{Choice of wavelength of analysis}

The optimal wavelength for API signal detection was determined to be $294 \mathrm{~nm}$. At this wavelength, least interference was exhibited by other possible substances present in commercial products as compared to $233 \mathrm{~nm}$.

\section{Method validation Linearity and range}

The data obtained (Figs. 2 and 3) showed good linearity (between 33.3 and $333.3 \%$ of the working concentration) for each of the two APIs. The coefficient of determination, $R^{2}$, was 0.9989 for both APIs.

\section{Precision}

Repeatability The CV of albendazole was $0.184 \%$ and $0.0 \%$ for mebendazole (Table 1 ). Since the CVs were below $2 \%$ [18], the developed method exhibited good repeatability.
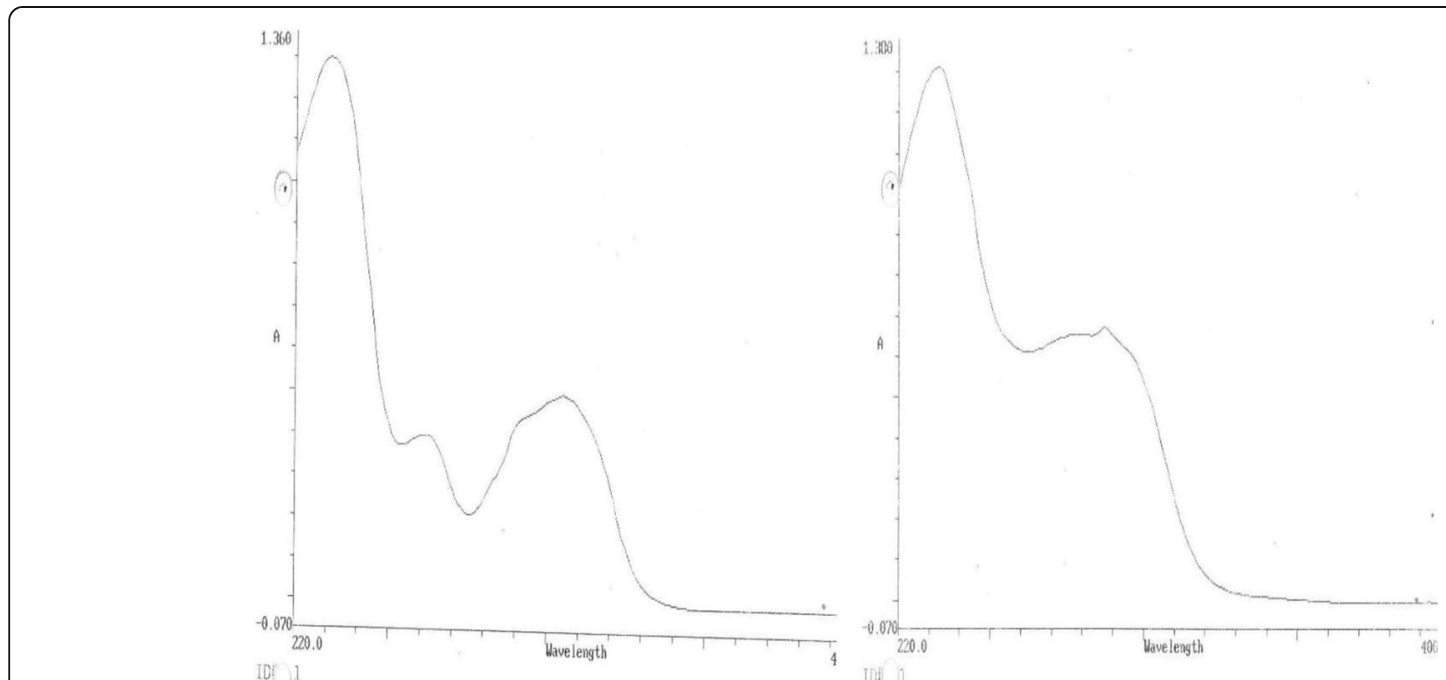

Fig. 2 UV absorption spectra for albendazole and mebendazole respectively in $0.1 \mathrm{M}$ methanolic $\mathrm{HCl}$ 


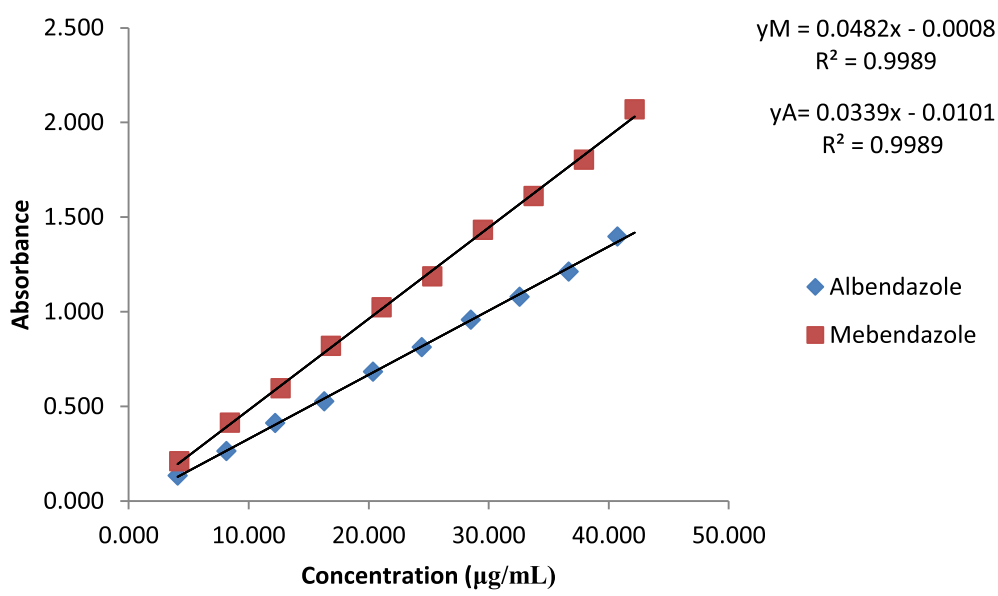

Fig. 3 Linearity plots for albendazole and mebendazole. $y \mathrm{~A}$ albendazole absorbance, $y M$ mebendazole absorbance, $x$ API concentration

Intermediate precision As shown in Table 1, the developed method showed good intermediate precision (given that the CV was less than $2 \%$ for both APIs) [10].

\section{Accuracy}

The data for recovery studies is presented in Table 2 .

The average recovery for the three levels for albendazole was $102.3 \%$ and $104.2 \%$ for mebendazole.

The Food and Drug Administration (FDA) of the USA requires that the recovery should be $100 \pm 2 \%$ at each concentration over the range of 80 to $120 \%$ of the working concentration [11].

Though the results (102.3\% and 104.2\% recovery for albendazole and mebendazole, respectively) were slightly above the upper limit at some concentrations for both APIs, the developed method exhibited acceptable accuracy. The method is more accurate for albendazole than mebendazole.

\section{Orthogonal HPLC analysis}

The percentage label claim for the selected analyzed product using HPLC was determined to be $106.6 \%$. This compared well with the $107.3 \%$ percentage content obtained with the developed method. This further confirms the accuracy of the developed method.

\section{Specificity}

For the developed method, the results of the recovery studies indicate that the method is capable of

Table 1 Repeatability and intermediate precision

\begin{tabular}{|c|c|c|c|c|c|c|}
\hline \multirow[t]{2}{*}{ API } & \multicolumn{3}{|c|}{ Repeatability } & \multicolumn{3}{|c|}{ Intermediate precision } \\
\hline & SD & RSD & CV (\%) & SD & RSD & CV (\%) \\
\hline Albendazole & 0.000447 & 0.001084 & 0.184 & 0.001 & 0.00230 & 0.230 \\
\hline Mebendazole & 0.00379 & 0.00579 & 0.579 & 0.001 & 0.00162 & 0.162 \\
\hline
\end{tabular}

SD Standard deviation, RSD Relative standard deviation, CV Coefficient of variation discriminating the analyte in the presence of the components likely to be present in the commercial products including excipients, related substances, and products of degradation. The method was therefore found to be specific for albendazole and mebendazole.

\section{Sensitivity}

The LOD and LOQ results were albendazole, LOD = $43.5 \mathrm{ng} / \mathrm{mL}$ and LOQ $=131.9 \mathrm{ng} / \mathrm{mL}$; for mebendazole, $\mathrm{LOD}=30.6 \mu \mathrm{g} / \mathrm{mL}$ and $\mathrm{LOQ}=92.7 \mathrm{ng} / \mathrm{mL}$. It is worth noting that while the working concentration is stated in micrograms, the LOD and LOQ are stated in nanograms. These relatively low figures imply high sensitivity of the developed method for both APIs [11].

\section{Assay of commercial products}

The assay results for the commercial products are summarized in Tables 3 and 4.

\section{Discussion}

Out of the 32 samples analyzed, five samples (15.6\%) did not comply with compendial specifications. From the information gathered in the field, albendazole is the more popular anthelminthic compared to mebendazole. This is because it is administered as a single dose and several low-cost generic brands are available. It is therefore of great concern when a low-cost generic brand fails to conform to compendial specification since these drugs are more affordable and therefore mostly used by a greater percentage of the population. It came as a surprise that a suspension of the innovator product of mebendazole had an overage of the API hence did not conform to compendial specification. This is because the innovator product is usually used as the gold standard when studying the pharmaceutical equivalence of generic products [12, 13]. Also, inter-batch variation was 
Table 2 Recovery at 80, 100, and 120\% of the working concentration

\begin{tabular}{llll}
\hline API & \multicolumn{3}{l}{ Recovery level (\%) } \\
\cline { 2 - 4 } & $\mathbf{8 0}$ & $\mathbf{1 0 0}$ & $\mathbf{1 2 0}$ \\
\hline Albendazole & 104.3 & 100.0 & 102.3 \\
Mebendazole & 106.6 & 104.6 & 101.5 \\
\hline
\end{tabular}

observed with product A002T, a tablet dosage form of albendazole which is a popular anthelminthic, with one batch of the product having an API overage thus not complying with the compendia specifications.

\section{Conclusion}

Post-marketing surveillance is an essential component of drug discovery and development and should routinely be performed by the pharmaceutical companies, drug regulatory authorities, and analytical laboratories to ascertain that marketed medicines meet compendial requirements

Table 3 Results of analyses of commercial products for albendazole

\begin{tabular}{|c|c|c|c|c|}
\hline Product code & Dosage form & Batch & Assay (\%) & Comment $^{\mathrm{a}}$ \\
\hline \multirow[t]{3}{*}{ A001S } & Suspension & 1 & 107.3 & Complies \\
\hline & & 2 & 108.4 & Complies \\
\hline & & 3 & 107.3 & Complies \\
\hline \multirow[t]{3}{*}{ A001T } & Tablets & 1 & 96.6 & Complies \\
\hline & & 2 & 98.6 & Complies \\
\hline & & 3 & 100.1 & Complies \\
\hline \multirow[t]{2}{*}{ A002S } & Suspension & 1 & 104.1 & Complies \\
\hline & & 2 & 105.0 & Complies \\
\hline \multirow[t]{3}{*}{ A002T } & Tablets & 1 & 98.3 & Complies \\
\hline & & 2 & 145.4 & Does not comply \\
\hline & & 3 & 96.9 & Complies \\
\hline \multirow[t]{3}{*}{ A003S } & Suspension & 1 & 98.0 & Complies \\
\hline & & 2 & 97.1 & Complies \\
\hline & & 3 & 96.2 & Complies \\
\hline \multirow[t]{2}{*}{ A003T } & Tablets & 1 & 96.8 & Complies \\
\hline & & 2 & 99.6 & Complies \\
\hline A004S & Suspension & 1 & 100.2 & Complies \\
\hline \multirow[t]{2}{*}{ A004T } & Tablets & 1 & 97.2 & Complies \\
\hline & & 2 & 95.9 & Complies \\
\hline A005S & Suspension & 1 & 87.2 & Does not comply \\
\hline A005T & Tablets & 1 & 103.3 & Complies \\
\hline A006T & Tablets & 1 & 93.3 & Complies \\
\hline A007S & Suspension & 1 & 109.0 & Complies \\
\hline A008T & Tablets & 1 & 100.3 & Complies \\
\hline A009S & Suspension & 1 & 7.9 & Does not comply \\
\hline
\end{tabular}

aUSP 2018 specification for content (not less than $90.0 \%$ and not more than $110.0 \%$ of the label claim)
Table 4 Assay results of mebendazole commercial products

\begin{tabular}{lllll}
\hline Product code & Dosage form & Batch & Assay (\%) & Comment $^{\mathbf{a}}$ \\
\hline M001S & Suspension & । & 112.9 & Does not comply \\
& & $\|$ & 111.5 & Does not comply \\
M001T & Tablets & I & 102.5 & Complies \\
& & $\|$ & 105.7 & Complies \\
M002S & Suspension & । & 103.4 & Complies \\
& & $\|$ & 100.0 & Complies \\
M002T & Tablets & । & 99.6 & Complies \\
\hline
\end{tabular}

aSP 2018 Specification for content (should not be less than $90.0 \%$ and not more than $110.0 \%$ of the label claim)

and hence assure their continued usefulness $[14,15]$. In low-resourced jurisdictions such as Africa, there is a dearth of more sophisticated analytical techniques and skilled manpower. Cheaper but accurate methods of analysis would therefore be more appropriate. Bearing this in mind, a UV spectroscopic method for the analysis of benzimidazole anthelminthics albendazole and mebendazole was developed and validated. When the method was applied to commercial products, it was found to work as reliably as it did for the bulk raw material. The method was found to be comparable to other validated compendial methods. It could therefore find applicability in the analysis of bulk raw materials and finished products in manufacturing establishments. Because of its simplicity, it can be particularly useful for post-marketing surveillance of quality by regulatory bodies. With portable UV spectrophotometers being available, kits can easily be developed for field analysis of samples on site.

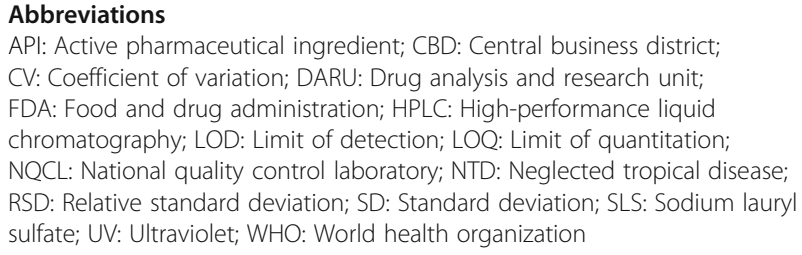

\section{Acknowledgements}

The authors wish to acknowledge the assistance accorded by Dr. H. K. Chepkwony and Dr. Mwaura of the National Quality Control Laboratory who facilitated the performance of orthogonal HPLC analysis using the facilities at their laboratory.

\section{Authors' contributions}

The current study is part of a thesis for the award of the degree of Master of Pharmacy in Pharmaceutical Analysis of the University of Nairobi conducted by JM under the supervision of the other three authors. BA was the lead supervisor assisted by PN and SN. JM did all the background research and the laboratory work. PN personally supervised and directed JM in the initial stages as he got acquainted to the operation of the UV spectrophotometer. All references in the thesis and manuscript were thoroughly reviewed by BA, $\mathrm{PN}$, and SN before insertion. SN was very instrumental in the acquisition of reference standards used in the research. All draft theses and the final document were thoroughly reviewed and corrected by BA, PN, and SN before the final document was prepared by JM. BA, PN, and SN edited the manuscript before its presentation to your distinguished journal. All the authors have read and approved the manuscript. 


\section{Funding}

This study was funded by funds kindly availed by the World Bank Through MAPRONANO ACE, Makerere University, Kampala, Uganda. The funding authority played no role whatsoever in the conduction of the study, data analysis, or writing of the manuscript.

\section{Availability of data and materials}

The data sets used and generated during the current study are available from the corresponding author on reasonable request.

Ethics approval and consent to participate

Not applicable

\section{Consent for publication}

Not applicable

\section{Competing interests}

The authors declare that they have no competing interests.

\section{Author details}

${ }^{1}$ Mount Kenya University, P O Box 342 - 01000, Thika, Kenya. ${ }^{2}$ University of Nairobi, P O Box 19676 - 00200, Nairobi, Kenya.

Received: 8 May 2020 Accepted: 31 August 2020

Published online: 20 October 2020

\section{References}

1. Hotez PJ, Brindley PJ, Bethony JM et al (2008) Helminth infections: the great neglected tropical diseases. J Clin Invest 118:1311-1321

2. Holden-Dye L, Walker RJ (2007) Anthelmintic drugs. WormBook 2:1-13

3. Bethony J, Brooker S, Albonico M et al (2006) Soil-transmitted helminth infections: ascariasis, trichuriasis, and hookworm. Lancet 367:1521-1532

4. Cook GC (1990) Use of benzimidazole chemotherapy in human helminthiases: indications and efficacy. Parasitol Today 6:133-136

5. Al-Kurdi Z, Al-Jallad T, Badwan A, Jaber AMY (1999) High performance liquid chromatography method for determination of methyl-5-benzoyl-2benzimidazole carbamate (mebendazole) and its main degradation product in pharmaceutical dosage forms. Talanta 50:1089-1097

6. De Ruyck H, Daeseleire E, De Ridder H, Van Renterghem R (2002) Development and validation of a liquid chromatographic-electrospray tandem mass spectrometric multiresidue method for anthelmintics in milk. J Chromatogr A 976:181-194

7. Agrawal VK, Chaturvedi S, Gupta A (2015) Simple and precise UV spectrophotometric method development for estimation of albendazole for dissolution study. Int J Pharm Sci Drug Res. 2015;7(1):120-2.

8. Nogales E (2001) Structural insights into microtubule function. Annual review of biophysics and biomolecular structure 30:397-420

9. Guideline IHT (2005) Validation of analytical procedures: text and methodology Q2 (R1). International conference on harmonization, Geneva, Switzerland

10. Shabir GA (2005) Step-by-step analytical methods validation and protocol in the quality system compliance industry. J Validation Technol 10:314-325

11. Shabir GA (2003) Validation of high-performance liquid chromatography methods for pharmaceutical analysis: understanding the differences and similarities between validation requirements of the US Food and Drug Administration, the US Pharmacopeia and the International Conference on Harmonization. Journal of chromatography A 987:57-66

12. Zuluaga AF, Agudelo M, Rodriguez CA, Vesga O (2009) Application of microbiological assay to determine pharmaceutical equivalence of generic intravenous antibiotics. BMC Clin Pharmacol 9:1

13. Vesga O, Agudelo M, Salazar BE et al (2010) Generic vancomycin products fail in vivo despite being pharmaceutical equivalents of the innovator. Antimicrob Agents Chemother 54:3271-3279

14. Alfadl AA, Abdoon S, Elamin M, Elnabi NG (2006) Quality of antimalarial drugs in Sudan: results of post-marketing surveillance. Sudanese J Public Health 1:108-111

15. Alomi YA, Kamal E, Alomi K (2016) National Drug Quality Reporting System at Ministry of Health in Saudi Arabia. J Pharmacovigilance 4:2

\section{Publisher's Note}

Springer Nature remains neutral with regard to jurisdictional claims in published maps and institutional affiliations.

\section{Submit your manuscript to a SpringerOpen ${ }^{\circ}$ journal and benefit from:}

- Convenient online submission

- Rigorous peer review

- Open access: articles freely available online

- High visibility within the field

- Retaining the copyright to your article

Submit your next manuscript at $\boldsymbol{\nabla}$ springeropen.com 